\title{
The Morphology of the Hypoglossal Dorsal Root and its Ganglia in Holstein Cattle
}

\author{
Sadullah BAHAR ${ }^{1)}$, Emrullah EKEN ${ }^{1) *}$ and Emrah SUR $^{2)}$ \\ ${ }^{1)}$ Departments of Anatomy and ${ }^{2)}$ Histology \& Embryology, Faculty of Veterinary Medicine, University of Selcuk, Campus, 42250, Konya- \\ Turkey
}

(Received 14 September 2005/Accepted 25 January 2006)

\begin{abstract}
This study was carried out to describe morphologically and morphometrically the hypoglossal dorsal root and its ganglia, using heads of 20 adult Holstein cattle of both sexes. The dorsal root of the hypoglossal nerve (XII) has always an evident dorsal root ganglion (DRG) including the accessory in $30 \%$ ( 6 of heads) or satellite ganglia in $10 \%$ ( 2 of heads). There were statistically significant differences between the lengths (right: $8.64 \pm 0.22 \mathrm{~mm}$, left: $7.91 \pm 0.31 \mathrm{~mm}, \mathrm{p}<0.01$ ) of peripheral roots of the DRG in male. Statistical significance existed in the lengths (right: $7.01 \pm 0.43$, left: $8.27 \pm 0.47, \mathrm{p}<0.05$ ) of the central roots of the DRG in male. Since the histological findings showed that each ganglion placed on the dorsal root of the XII had the general feature of a spinal ganglion, it can be said that the XII has the intracranial peripheral (sensory) fibers and carry directly sensory input to the brain stem. In conclusion, the present study is the first to reveal the morphology of the hypoglossal dorsal root with ganglia in Holstein cattle.

KEY WORDS: accessory ganglion, cranial nerve, morphometry, sensory neuron.
\end{abstract}

J. Vet. Med. Sci. 68(6): 533-536, 2006

Numerous anatomical $[1,12,13]$ and electrophysiological studies $[1,6,11]$ have been carried out to investigate peripheral fibers of the XII. Due to their extracranial connections with some other cranial nerves, the hypoglossal peripheral (sensory) fibers were reported to be related to cell bodies within the trigeminal ganglion of the trigeminal nerve $(\mathrm{V})[3,8]$, or within the superior $[8,10]$ and inferior [10] ganglia of the glossopharyngeal nerve (IX), or within the superior (jugular) $[8,10]$ and inferior (nodose) $[10,13]$ ganglia of the vagal nerve $(\mathrm{X})$, or within the spinal ganglia of the $\mathrm{C} 1, \mathrm{C} 2$ and $\mathrm{C} 3$ segments $[8,10]$. Sensory cells have been also reported to be present along the extracranial course of the XII $[6,12,13]$.

Froriep and Beck [4] first studied the dorsal root of the XII in the embryos of various mammals, and concluded that in ox and sheep the dorsal hypoglossal root and ganglion were strongly developed and constant for life. Hollinger [7] also described that a dorsal root with a ganglion in the XII existed in a transitory manner in certain mammal embryos or fetuses (calf, pig, sheep, molossian dog, otter, rabbit), and then disappeared during ontogenesis but persisted mainly in the ungulated adult individuals.

Recently, the dorsal root of the XII has been also grossly described in a rather superficial manner in the domestic ruminants $[2,5]$. Moreover, in the literature no morphological information on the intracranial segment of the XII of Holstein cattle is available at present. We thus decided to investigate morphologically and morphometrically the hypoglossal dorsal root and its ganglia in this species.

\section{MATERIALS AND METHODS}

A total of 20 heads of adult Holstein cattle of both sexes

\footnotetext{
* Correspondence to: Assoc. Prof. Dr. Eken, E., Department of Anatomy Faculty of Veterinary Medicine, University of Selcuk, Campus, 42250, Konya, Turkey.
}

aged 3-4 years and weighing between $400-500 \mathrm{~kg}$ were used. All heads were obtained from the Kon-et Slaughterhouse in Konya, Turkey. After the extracranial soft and hard tissues of the heads were removed by the conventional methods, the specimens were transferred into containers with $10 \%$ formaldehyde solution. Then, the dorsal root of the XII and its ganglia on both sides of the heads were investigated both macroscopically and under a stereomicroscope (Nikon SMZ-2T, Nikon Corp., Tokyo, Japan); moreover, the ganglia taken from the specimens dissected were studied histologically. For routine histological examinations, the tissue samples were fixed in $10 \%$ buffered-formaldehyde (pH 7.4), dehydrated, cleared and embedded in paraffin blocks and cut in 6- $\mu \mathrm{m}$ thick longitudinal sections which were stained with Crossman's trichrome stain. The histological preparations were examined using a light microscope (Nikon E-400 attached with DS-5M digital camera and DS-L1 Camera control unit). Morphometrical measurements of the lengths (cranial to caudal) and widths (lateral to medial) of the DRG and accessory ganglion (AG) were performed using an ocular micrometer (Olympus). The lengths of the peripheral and central roots of the DRG and AG and the distance between the terminal point of the most caudal central root of the DRG and the most cranial central root of the first spinal ganglion were measured using a digital calliper (Mitutoyo 500 171-1 Digimatic Calliper $150 \mathrm{~mm} / 6 \mathrm{in}$, Japan). Moreover, the numbers of the central roots of each DRG examined were counted and added to parameters mentioned above. All statistical analyses were accomplished with the Statistical Package for the Social Sciences (SPPS 9.0, SPPS Inc. Corp, Chiago, IL, U.S.A.) computer package.

\section{RESULTS}

Dissection findings: A prominent DRG that extended mediolaterally was detected in both sides of all materials 
(Figs. 1-5). It, a mostly shuttle or much rarely irregular shaped, was located in a subarachnoideal space where the accessory nerve (XI) and the denticulate ligament crossed each other just ventral to this ganglion (Fig. 1). In all materials a peripheral root, after originating from the dorsal surface of the XII, ran dorsomedially to reach ventral to the first denticulate ligament. Immediately penetrating the first denticulate ligament attached to the dura mater (Fig. 1), this peripheral root coursed medially a short distance to join the lateral extremity of the DRG by mostly falling to pieces before its termination (Fig. 4). Then, the central roots emerged separately from the medial extremity of the DRG to terminate independently in the dorsal lateral sulcus of the medulla oblongata (Figs. 1-3). Moreover, 2 female materials $(5 \%)$ had bilaterally a satellite ganglion (SG) (Fig. 4) that was located immediately cranial to the DRG. The SG was also connected to the DRG by an interganglioner fiber. It is of interest that this SG received both an evident peripheral root from the peripheral root of the main ganglion in a ventral direction and a thin peripheral root from the spinal part of XI in a cranial direction. Its central root joined the dorsal lateral sulcus of the medulla oblongata.

In addition to the DRG in 6 materials (30\%), an accessory ganglion (AG), a shuttle-shaped, existed on both side in 3 of them ( 2 females, 1 male), on the right in 2 females and on the left in 1 female. The AG was located about $15 \mathrm{~mm}$ cranial to the DRG at which level it had dorsolaterally intimate contact with the XI (Figs. 2, 5). It received a peripheral root from the cranial bundle of the XII. Running a short distance on the medial surface of the XI, the central root of the AG joined directly the medulla oblongata just near the vagal roots. This study revealed that whenever a SG existed on the hypoglossal dorsal root, an AG was absent on that side. We also

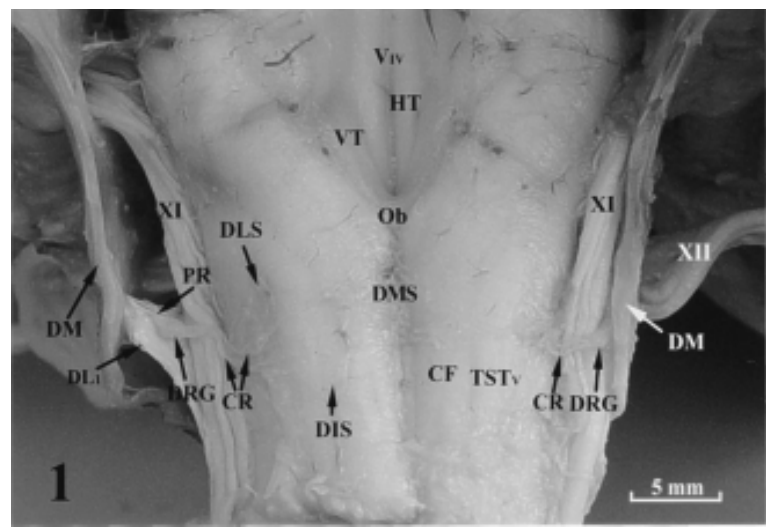

Fig. 1. Dorsal view of medulla oblongata. Abbreviations: AG: Accessory ganglion; Ar: Arachnoid; CF: Cuneata fascicle; CR: Central root; DIS: Dorsal intermedian sulcus; $\mathrm{DL}_{1}$ : First denticulate ligament; DLS: Dorsal lateral sulcus; DM: Dura mater; DMS: Dorsal median sulcus; DRG: Dorsal root ganglion; HT: Hypoglossal triangle; IF: Interganglioner fiber; Ob: Obex; PR: Peripheral root; SG: Satellite ganglion; $\mathrm{TST}_{\mathrm{V}}$ : Tubercle of spinal tract of trigeminal nerve; VT: Vagal triangle; $\mathrm{V}_{\mathrm{IV}}$ : Fourth ventricle; IX: Glossopharyngeal nerve; X: Vagal nerve; XI: Accessory nerve; XII: Hypoglossal nerve. reported that whenever a material contained a DRG or the latter with an AG, it had single (Figs. 1,3) or double peripheral root (Figs. 2, 5) emerging from the XII, respectively.

In this study, we recorded that the length and width of the DRG had no statistical significance within or between both sexes. We found statistical differences between the lengths (right: $8.64 \pm 0.22 \mathrm{~mm}$, left: $7.91 \pm 0.31 \mathrm{~mm}, \mathrm{p}<0.01$ ) of peripheral roots of the DRG in male. Moreover, the total values (right: $8.70 \pm 0.22 \mathrm{~mm}$, left: $7.98 \pm 0.27 \mathrm{~mm}, \mathrm{p}<0.05$ ) of the lengths of peripheral roots of the DRG of both sexes

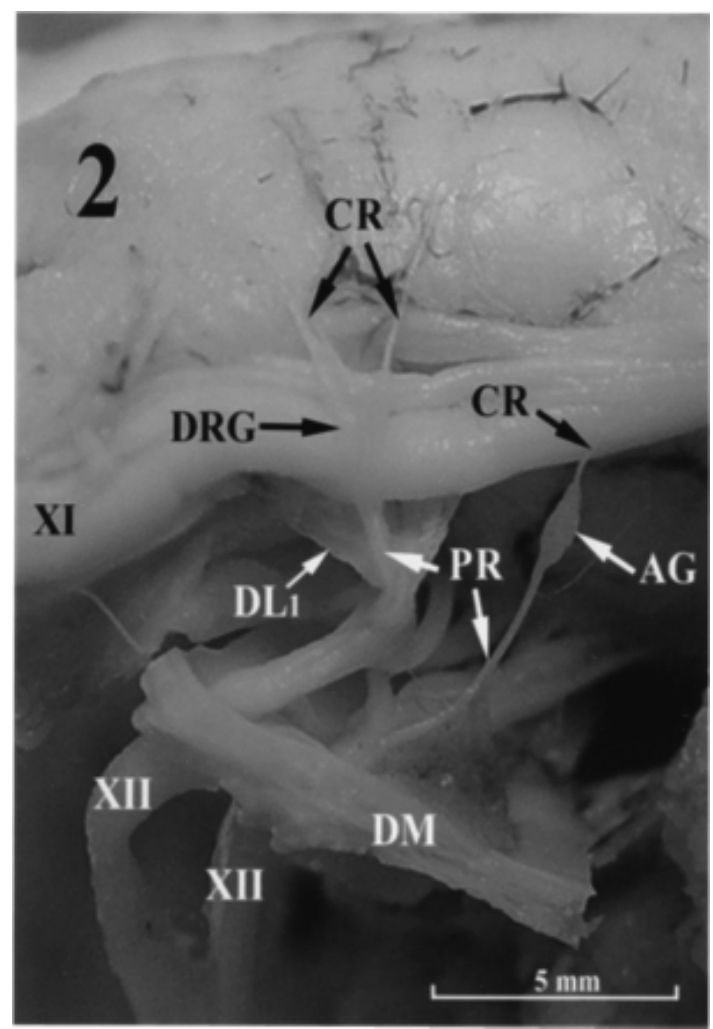

Fig. 2. Localization of dorsal root ganglion (DRG) and accessory ganglion (AG), right lateral view. Abbreviations as for Fig. 1.

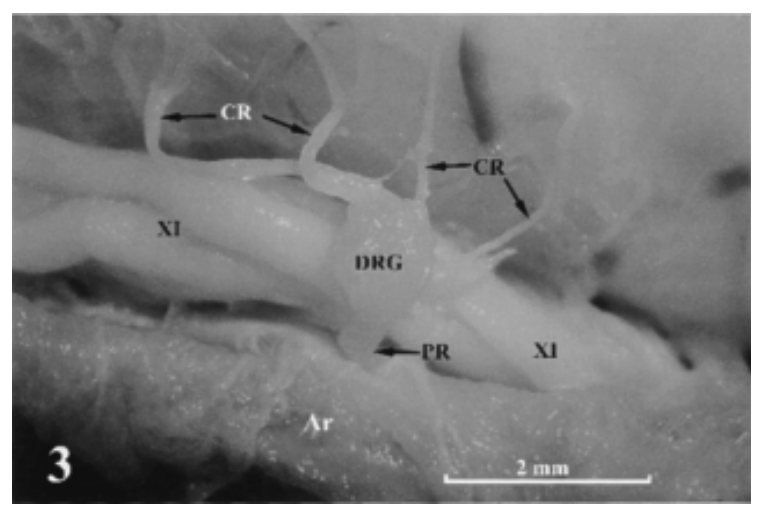

Fig. 3. Localization of dorsal root ganglion (DRG), left dorsal view, Ar is drawn ventrally. Abbreviations as for Fig. 1. 


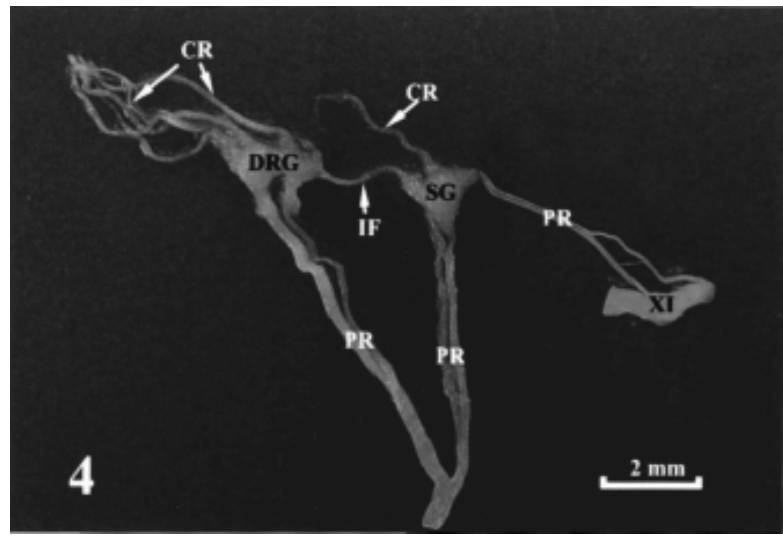

Fig. 4. Peripheral and central roots of dorsal root ganglion (DRG) and satellite ganglion (SG), right lateral view. Abbreviations as for Fig. 1.

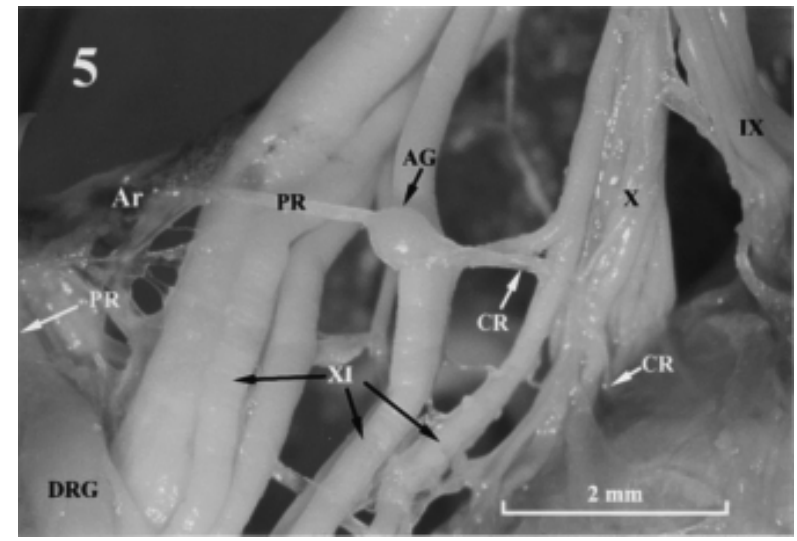

Fig. 5. Localization of accessory ganglion (AG), left dorsal view. Abbreviations as for Fig. 1.

Table 1. Parameters of dorsal root ganglion. Measurements and enumerations were analyzed by paired $t$ test and Mann-Withney U test, respectively

\begin{tabular}{|c|c|c|c|c|c|c|c|}
\hline & \multicolumn{2}{|c|}{ Male } & \multicolumn{2}{|c|}{ Female } & \multicolumn{2}{|c|}{ Both Groups } & \multirow[b]{2}{*}{ Total(n:40) } \\
\hline & Right (n: 10) & Left (n: 10) & Right (n: 10) & Left (n: 10) & Right (n: 20) & Left (n: 20) & \\
\hline $\mathrm{L}$ of $\mathrm{DRG}(\mathrm{mm})$ & $2.45 \pm 0.23$ & $2.43 \pm 0.29$ & $2.40 \pm 0.19$ & $3.36 \pm 0.20$ & $2.43 \pm 0.15$ & $2.40 \pm 0.17$ & $2.41 \pm 0.11$ \\
\hline Range & $1.5-4.0$ & $1.5-4.5$ & $1.3-3.3$ & $1.7-3.5$ & $1.3-4$ & $1.5-4.5$ & $1.3-4.5$ \\
\hline W of DRG (mm) & $1.31 \pm 0.07$ & $1.28 \pm 0.09$ & $1.32 \pm 0.10$ & $1.38 \pm 013$ & $1.32 \pm 0.06$ & $1.33 \pm 0.08$ & $1.32 \pm 0.05$ \\
\hline Range & $1.2-1.7$ & $0.9-1.8$ & $0.8-2.0$ & $1.0-2.3$ & $0.8-2$ & $0.9-2.3$ & $0.8-2.3$ \\
\hline $\begin{array}{l}\mathrm{L} \text { of PR of } \\
\text { DRG (mm) }\end{array}$ & $8.64 \pm 0.22 * *$ & $7.91 \pm 0.31 * *$ & $8.76 \pm 0.44$ & $8.05 \pm 0.45$ & $8.70 \pm 0.24 *$ & $7.98 \pm 0.27 *$ & $8.34 \pm 0.18$ \\
\hline Range & $7.2-9.2$ & $6.3-9.4$ & $7.0-11.5$ & $6.1-10.3$ & $7.0-11.5$ & $6.1-10.3$ & $6.1-11.5$ \\
\hline $\mathrm{N}$ of $\mathrm{CR}$ of $\mathrm{DRG}{ }^{\S}$ & 4.00 & 3.50 & 4.50 & 4.00 & 4.00 & 4.00 & 4.00 \\
\hline Range & $3-5$ & $3-7$ & $3-5$ & $3-5$ & $3-5$ & $3-7$ & $3-7$ \\
\hline $\begin{array}{l}\text { L of CR of } \\
\text { DRG }(\mathrm{mm})\end{array}$ & $7.01 \pm 0.43^{*}$ & $8.27 \pm 0.47 *$ & $8.28 \pm 0.53$ & $7.63 \pm 0.44$ & $7.65 \pm 0.36$ & $7.95 \pm 0.32$ & $7.80 \pm 0.24$ \\
\hline Range & $5.30-10.0$ & $6.2-10.7$ & $6.2-11.1$ & $5.5-9.5$ & $5.3-11.1$ & $5.5-10.7$ & $5.3-11.1$ \\
\hline $\begin{array}{l}\text { Distance between } \\
\text { TP1-TP2 (mm) }\end{array}$ & $6.17 \pm 0.59$ & $5.90 \pm 0.37$ & $6.23 \pm 0.31$ & $6.82 \pm 0.53$ & $6.20 \pm 0.33$ & $6.36 \pm 0.34$ & $6.28 \pm 023$ \\
\hline Range & $1.3-10.1$ & $3.9-7.1$ & $4.7-7.6$ & $4.4-9.8$ & $1.3-10.1$ & $3.9-9.8$ & $1.3-10.1$ \\
\hline
\end{tabular}

$*$ and $* *$ mean that differences among the means of different groups in the same line are statistically significant in value of $\mathrm{p}<0.05$ and $\mathrm{p}<0.01$, respectively. Data expressed as the mean \pm SEM except $\S$ in which as median.

Table 2. Morphometrical measurements of accessory ganglion

\begin{tabular}{lccc}
\hline & Right (n: 5) & Left (n: 4) & Total (n: 9) \\
\hline L of AG (mm) & $1.34 \pm 0.19$ & $1.50 \pm 0.21$ & $1.41 \pm 0.01$ \\
Range & $0.8-1.7$ & $1.1-2$ & $0.8-2$ \\
W of AG (mm) & $1.04 \pm 0.07$ & $1.15 \pm 0.12$ & $1.09 \pm 0.06$ \\
Range & $0.8-1.2$ & $1-1.5$ & $1-1.5$ \\
L of PR of AG (mm) & $8.46 \pm 0.70$ & $9.33 \pm 0.02$ & $8.84 \pm 0.87$ \\
Range & $6.2-10.5$ & $5.2-13.5$ & $6.2-13.5$ \\
L of CR of AG (mm) & $7.64 \pm 0.51$ & $7.53 \pm 0.02$ & $7.59 \pm 0.79$ \\
Range & $(6.7-9.2)$ & $(4.3-12.7)$ & $(4.3-12.7)$ \\
\hline
\end{tabular}

Since data was not bilateral, descriptive statistic was performed. Data expressed as the mean \pm SEM.

Tables 1, 2. AC: Accessory ganglion, CR: Central root, DRG: Dorsal root ganglion, L: Length, N: Number, PR: Peripheral root, TP1: terminal point of the most caudal CR of DRG, TP2: terminal point of the most cranial CR of the first spinal ganglion, W: Width. had a statistical significance. The numbers of central roots of the DRG ranged from 3 to 5 or from 3 to 7 in the right and left sides, respectively. Statistical significance existed in the lengths (right: $7.01 \pm 0.43$, left: $8.27 \pm 0.47, \mathrm{p}<0.05$ ) of the central roots of the DRG in male. Interestingly, although the distance between the terminal point of the most caudal central root of the DRG in medulla oblongata and the terminal point of the most cranial central root of the first spinal ganglion in medulla oblongata presented striking individual differences, it had no statistical significance within or between both sexes. The means of the length and width of a total of 9 AG determined in this study were $1.41 \pm 0.01$ and $1.09 \pm$ 0.06 , respectively. The lengths of peripheral and central roots of the AG were means $8.84 \pm 0.87$ and $7.59 \pm 0.79$, respectively. Data regarding all morphometrical measurements obtained from the present study were shown in Tables 1 and 2 . 


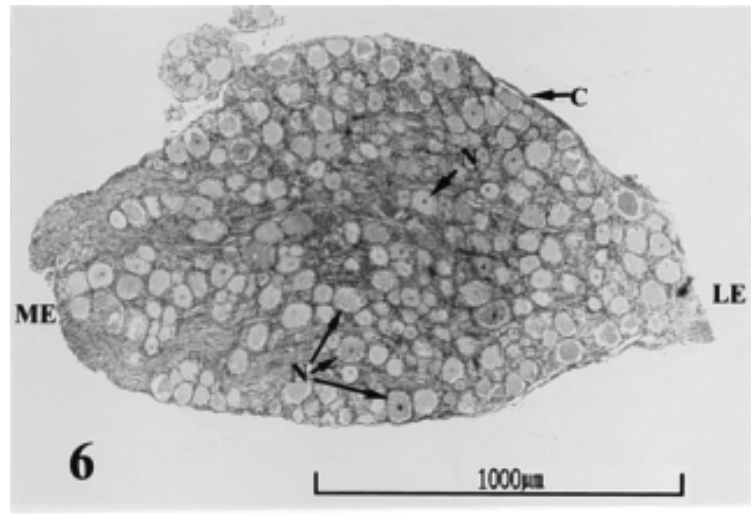

Fig. 6. Longitudinal section of dorsal root ganglion (DRG).

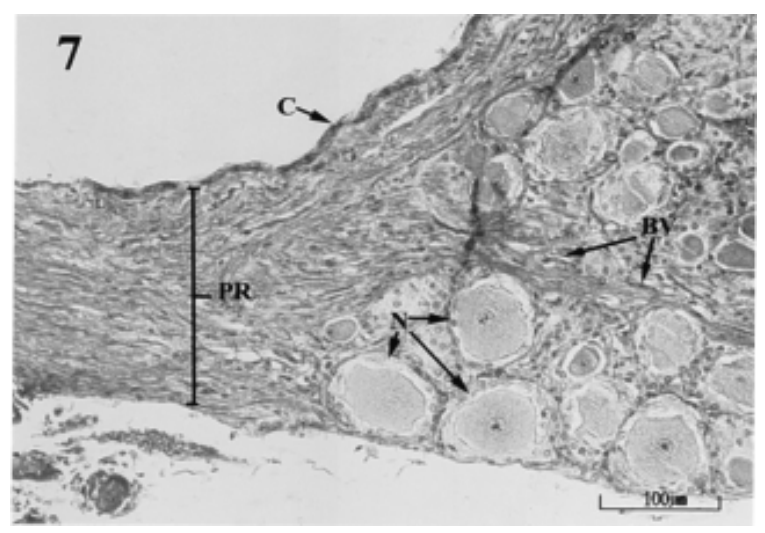

Fig. 7. Longitudinal section of lateral extremity of accessory ganglion (AG). Figs. 6, 7.A: Axon; BV: Blood vessels; C: Capsule; DM: Dura mater; LE: Lateral extremity; ME: Medial extremity; N: Neuron.

Histological findings: In cross sections through all ganglia mentioned above, it was demonstrated usual spinal ganglion structure (Figs. 6, 7). The ganglion was enclosed by a capsule formed by the connective tissue. The large and round neurons which have euchromatic nucleus and clear nucleolus have been surrounded by many satellite cells. There were many myelinated and unmyelinated axons travelling in different directions in the ganglia.

\section{DISCUSSION}

Holstein cattle has a dorsal root with a ganglion as mentioned earlier $[2,4,5,7]$ in other ruminants. Moreover, the present study revealed that a SG or an AG can be sometimes attached to the dorsal roots of the XII in Holstein cattle. We noted that when a SG was present on the dorsal root of the XII, it received continuously a peripheral root from the XI. We showed that the XII of this species has the intracranial peripheral fibers including a small intracranial sensory contribution of the XI in 2 materials and carry directly sensory input to upper centers of the brain in addition to its extracra- nial peripheral fibers related to other cranial nerves. The histological findings of our study also revealed that each ganglion examined in this study had the general feature of a spinal ganglion as has been described in the literature [9].

Consequently, the present study is the first to describe morphologically and morphometrically the dorsal root of the DRG of the XII, and its ganglia in Holstein cattle. However, we think that further studies are required to reveal thoroughly sensory function of the XII in Holstein cattle and to detect terminal projections of its sensory fibers in brain stem, using a retrograde tracer such as horseradish peroxidase etc. We hope that the results from this study will throw light on the future experimental studies on the nervous system, and that it contributes considerably to the present anatomical knowledge regarding the intracranial portion of the XII in this species.

ACKNOWLEDGEMENT. The authors are deeply grateful to the Selcuk University Research Fund (No. 96/175) for the financial support.

\section{REFERENCES}

1. Blom, S. 1960. Afferent influences on tongue muscle activity. A morphological and physiological study in the cat. Acta Physiol. Scand. 49: 1-97.

2. Cui, S. 1996. Gross anatomy of the hypoglossal nerve in the Bactrian camel. J. Lanzhou Univ. (Nat. Sci.) 31 (Morph. Suppl.): 123-125.

3. Fitzgerald, M. J. T. and Law, M. E. 1958. The peripheral connexions between the lingual and hypoglossal nerves. J. Anat. 92: $178-188$.

4. Froriep, A. and Beck, W. 1895. Uber das vorkommen dorsaler hypoglossuswurzeln mit ganglion, in der Reihe der Saugetiere. Anat. Anz. 10: 688-696.

5. Godinho, H. P. and Getty, R. 1975. Peripheral nervous system. pp. 1081-1124. In: Sisson and Grassman's the Anatomy of the Domestic Animals, vol. 1, 5th ed. (Getty, R. ed.), W. B. Saunders Co., Philadelphia.

6. Hanson, J. and Widen, L. 1970. Afferent fibers in the hypoglossal nerve of cat. Acta Physiol. Scand. 79: 29-36.

7. Hollinger, A. 1955. Constitution of the loop of the hypoglossal nerve; study of comparative anatomy. Arch Anat. Histol. Embryol. 38: 1-46.

8. Nazruddin, S. S., Shirana, Y., Yamauchi, K. and Shigenaga, Y. 1989. The cells of origin of the hypoglossal afferent nerves and central projections in the cat. Brain Res. 490: 219-235.

9. Ross, M. H. and Reith, E. J. 1985. Histology: A Text and Atlas. Harper\& Row, Publishers, L. B. Lippincott Co., Philadelphia.

10. Takeuchi, Y., Hayakawa, T., Ozaki, H. S., Kito, J., Satoda, T. and Matsushima, R. 1990. Afferent fibers in hypoglossal nerve: a horseradish peroxidase study in cat. Brain Res. Bull. 24: $81-87$.

11. Tanaka, T. 1975. Afferent projections in the hypoglossal nerve to the facial neurons of the cat. Brain Res. 99: 140-144.

12. Wozniak, W. and Young, P. A. 1968. Nerve cells in the extracranial portion of the hypoglossal nerve in human fetuses. Anat. Rec. 162: 517-522.

13. Zimny, R., Sobusiak, T. and Matlosz, Z. 1970. The afferent components of the hypoglossal nerve. J. Hirnforsch. 12: 83100. 